\title{
Countermeasure Analysis for Taobao Newbie's Developing Logistics Financial Business
}

\author{
Xiuli Tan, Mingyue Ai ${ }^{1}$ \\ Business College, Yantai Nanshan University, Yantai, China
}

\begin{abstract}
Carry out analysis on risk issue about Taobao Newbie's developing logistics financial business using literature method and survey method. It is indicated by research that there're internal operation, policy environment and industry environment risks during Taobao Newbie's developing logistics finance. So countermeasures such as improving business process and monitoring system, supplementing policy defects and establishing risk alarming system etc. have been put forward. Research results have reference significance for e-shopping websites to avoid risks during developing logistics finance business.
\end{abstract}

Index Terms - Taobao Newbie; logistics finance; risk; countermeasure

\section{Introduction}

E-commerce in China is undergoing a rapid development, and Taobao Newbie Logistics Finance, as a relatively renowned large-scaled comprehensive shopping website in China, needs to keep pace with logistics finance. Taobao Newbie belongs to Alibaba Group, with professional support from technical personnel and strong financial support. According to statistics in 2014, there're about 5.6 million Taobao Newbie sellers, which are mainly middle and largesized enterprises, so it could be seen that, Taobao Newbie's developing logistics finance business, could not only promote website's development and improvement, but promote regional economic development. Taobao Newbie has its own logistics network system, which has effectively shortened financing time for middle and small-sized enterprises. Taobao Newbie has its own payment tool - Alipay, which binds information such as personal ID information and contact etc. of corporation legal person, safe and convenient. It has effectively simplified loan procedures for middle and smallsized enterprises and solved information leakage problem.

Although the time since the launching of Taobao Newbie's logistics finance service is very short, it is now undergoing an extremely rapid speed. In 2012, Juhuasuan platform launched the Taobao Newbie credit loan, and 20 thousand middle and small-sized logistics enterprises applied within several minutes, with a total loan exceeding 1.4 billion Yuan, while middle and small-sized enterprises call it as the easiest loan. This form has not only reduced loan threshold, simplified loan process, but saved time.

\section{A. Financing process of application for Taobao Newbie logistics finance business}

Step one Middle and small-sized enterprises need to register as a seller user on Taobao Newbie, and improve enterprise information.

Step two Middle and small-sized enterprises submit financing application for logistics finance to the website, which will carry out diagnosis on middle and small-sized enterprises' goods as pledge supervisor, to judge whether it complies with financing modes such as direct financing, warehouse receipt pledge or logistics credit etc.

Step three If conditions are met, the website will obtain financing from the bank regarding middle and small-sized enterprises' goods as pledge.

Step four The bank will issue financing loan to middle and small-sized enterprises applying for financing loan according to related information provided by the website.

It is a win-win situation as for Taobao Newbie, on one hand, it provides service fee for middle and small-sized enterprises to apply for financing, on the other hand, it provides supervision fee for goods pledge party of the bank; for middle and small-sized enterprises, this has solved finance bottleneck in the difficulty of financing for companies in a simple way. For bank, it meets diversified developing trend of the bank, and obtains new profits as well.

\section{B. Taobao Newbie registered enterprise financing requirements analysis}

In Dec. 2014, the author has collected and read large quantities of literature and materials, while carried out field visit and investigation on Taobao Newbie's logistics finance's development, adopting interviewing combined with questionnaire. In the recycled 47 questionnaires, there're 47 middle and small-sized enterprises are private ones.

First, financing means.

\footnotetext{
${ }^{1}$ Author introduction: Tan Xiuli (1973- ), female, postgraduate, Business College, Yantai Nanshan College, teacher; Ai Mingyue (1982-), female, postgraduate, teacher of Business College of Yantai Nanshan College; address: 16\#202, Donghai District, Yantai Nanshan College, Longkou City, Shandong Province Zip code: 265713 Mobile: 15053545879 Email: 1102819122@qq.com

Subject:

This dissertation is a periodical achievement of 2014 Yantai Social Science Planning Research Project - Yantai Supply Chain Financial Ecological Environment Optimization Research [YTSK-028];

Fund project: This dissertation is a periodical achievement of 2014 Yantai Nanshan College Youth Teacher Science Research Fund Project - Based on Regional Economic Development's Logistics Finance Mode and Risk Management Research [201408]
} 


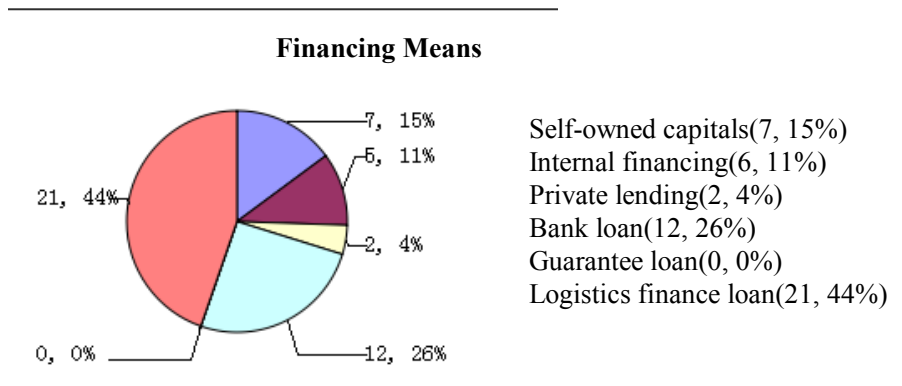

Fig. 3.1 Financing Means

Most enterprises have loans to different extent, and only 7 enterprises have its own capitals, accounting for $15 \%$ of those investigated. 12 enterprises mortgage part of assets to the bank to obtain loans, accounting for $26 \%$ of those investigated. 5 enterprises raise funds internally, accounting for $11 \%$ of those investigated. 21 enterprises obtain loans via logistics enterprises, accounting for $44 \%$ of those investigated. 2 enterprises use private lending, accounting for $4 \%$ of those investigated. However, there's no enterprise use guarantee loan.

Second, the reason of shortage of funds.

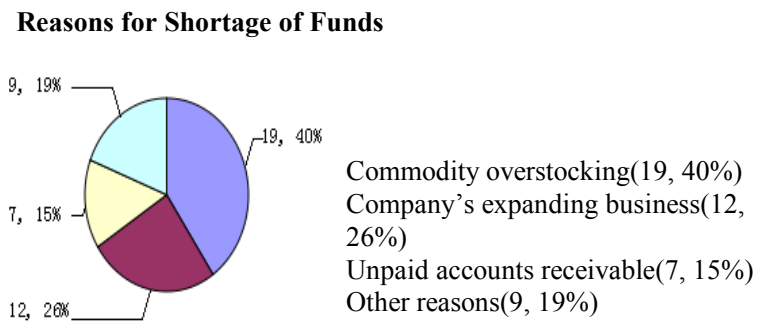

Fig. 3.2 The Reason of Shortage of Funds

From the icon, it could be seen that reasons for shortage of funds in most enterprises lie in commodity overstocking in 19 enterprises, which accounts for $40 \%$ of those investigated, the need to enlarging business scope of the company in 12 enterprises, which accounts for $26 \%$ of those investigated, unsound capital circulation because of unpaid accounts receivable in 7 enterprises, which accounts for $15 \%$ of those investigated, and other loan reasons for 9 enterprises, which accounts for $19 \%$ of those investigated.

Third, factors impacting loan.

\section{Factors Impacting Loan}

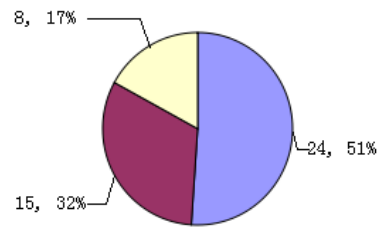

Loan interest rate $(24,51 \%)$ Simple and quick $(15,32 \%)$ Other reasons $(8,17 \%)$

Fig. 3.3 Factors Impacting Loan
From the above chart it could be concluded that: $51 \%$ enterprises focus on loan interests, which directly impacts the enterprise's benefits. 15 enterprises select simple and quick financing means, accounting for $32 \%$ of those investigated, and 8 enterprises think other factors will impact loans, i.e. relatives in bank makes it easier to loan, accounting for $17 \%$ of those investigated.

From the above questionnaire investigation analysis, it could be concluded that: It is very difficult for middle and small-sized enterprises to apply for a bank loan, besides, the procedure is complicated, requiring them to mortgage part of assets, with a large financing gap. Taobao Newbie's logistics finance loan is short in time and simple in procedure, with its own payment tool, making middle and small-sized enterprises need not to worry about business information leakage etc., so Taobao Newbie logistics finance, as an emerging financing way, has a huge developing potential.

\section{Risks in Taobao Newbie's Developing Logistics Finance}

\section{A. Operation Risk}

In recent years, Taobao Newbie logistics finance business has undergone a rapid development, however, the developing degree is not that sound. First, talent shortage. At present, there's a relatively huge gap in logistics talent, and there're few professional persons in high schools and social training institutions. In addition, Taobao's using management personnel only knowing website management has resulted in certain limitation, i.e. limitation in logistics knowledge and logistics business etc.

Second, technology risk. Lagging technology makes relatively high logistics fee in China. Logistics finance business in China generates together with third party logistics enterprises, while existing assets assessing system, and enterprise credit assessing system etc. are not that sound, making asynchronous or unsymmetrical phenomenon between Taobao Newbie and banks \& enterprises, making Taobao Newbie logistics finance needs to undertake other risks other than those of its own.

Third, operation risk. Taobao Newbie, engaged in finance business, for the need to deepen into customer's production \& distribution supply chain to provide diversified service, operation scope has been enlarged, which also increases risks. From the enterprise's application for loan to inter bank business, operation risk in Taobao Newbie logistics finance is everywhere. At present, logistics finance business in China is at its initial stage in extensive form, so operation risk in Taobao Newbie's developing logistics finance could not be neglected.

\section{B. Environment risk both at home and abroad}

Environment risk means the change in policy system and economic environment. Taobao Newbie's developing logistics finance business does not only need to undertake risks caused by China's political and economic environment but risks from international environment change, i.e. the risk of exchange rate change. On the other hand, according to Chinese laws, Taobao Newbie could not found its own financial department via 
acquiring banks like UPS, which not only impacts Taobao Newbie's implementing logistics finance, but limits the growth in China's logistics finance business to a greater extent. It seems that multiple laws released by far on logistics (like Contract Laws and Property Law etc.) have not definitely defined enterprise responsibility right issue on logistics finance business.

\section{Industry environment risk}

First, credit risk. The development in logistics finance business in China is not that sound, and its mechanism needs to be improved. There's no written agreement during pledged assets assessment, so it is unable to carry out assessment on enterprise's actual situation in a reasonable and objective manner;

It is unknown whether the person carrying out pledged assets assessment has received bribes from enterprises or conducted deceits; when the enterprise applying for a loan fails to repay on schedule while the pledge value is insufficient, Taobao Newbie logistics finance, as the guarantee for enterprise, needs to repay the outstanding debts for enterprise, and all these are risks from enterprises need to be undertaken by Taobao Newbie. Secondly, operation safety risks. During the process of middle and small-sized enterprises applying for financing via Taobao Newbie logistics finance, Taobao Newbie needs to undertake any leakage risk of customer information caused by its own network system, as well as any customer loss caused by network system during online trading.

Besides, Taobao Newbie's developing logistics finance also needs to undertake various losses during pledge in stock, stock safety, employee integrity as well as credibility of $\mathrm{B} / \mathrm{L}$ etc.

\section{Countermeasures for Taobao Newbie to Avoid Risks during Developing Logistics Finance}

\section{A. Comprehensive control on operation risk}

1. Improve business process and monitoring system. First, constantly improve Taobao Newbie's logistics finance business process, for constantly improving Taobao Newbie's logistics finance business process and monitoring policy is an effective manner to prevent operation risk. Second, improve internal monitoring system. During the implementation of Taobao Newbie's logistics finance business, Taobao Newbie needs to set an independent credit assets management department, so as to reduce operation risk via two reviews, and mutual supervision between assessors and credit management persons. Carry out all-round supervision on pledge storage, stock check and delivery as well as price fluctuation etc. of financing enterprises, to find hidden risks and to enhance risk prevention ability. 2. Enhance internal management. On one hand, to take its place in domestic market, Taobao Newbie's logistics finance needs to accelerate its opening up to the outside, pay attention to intelligentize logistics finance, develop and establish a logistics finance system for its website. On the other hand, it is required to enhance logistics quality cultivation among personnel inside Taobao Newbie logistics finance, carry out trainings on employees relying on high schools or training institutions, introduce and absorb excellent talents both at home and abroad in an active stance, while introduce advanced management methods and management systems. In addition, special persons will be responsible for investigating the credit of the enterprise applying for financing, as well as the value of pledge, meanwhile, it is also required to judge the legality of pledged commodities correctly.

\section{B. Multiple means to supplement system insufficiency}

On one hand, construct an information sharing platform. Taobao Newbie realizes timely information sharing of financial institutions and financing enterprises, while obtains real-time information of capital flow and logistics, besides, it could also carry out real-time dynamic monitoring and analysis on financing enterprise's operation behaviors. Taobao Newbie could consider interconnecting its own information platform with large-scaled trading markets and information suppliers, to realize more sufficient information sharing.

One the other hand, improve legal system. At present, there're no definite laws or regulations to specify contract terms and pledge ownership in logistics finance, while there's no legal restriction on logistics finance industry. Government department shall cooperate with specialists in all walks of life to make related articles of law to restrict, meanwhile, it shall also accelerate improving enterprise's credit registration system, and establish laws matching property publication filing system etc.

\section{Improve risk alarming mechanism}

First, enhance risk control. In risk monitoring mechanism, Taobao Newbie's implementing logistics finance business is facing wide middle and small-sized enterprise customers, and the operation stability is greatly lower than that of large-sized enterprises, so it is required to enhance pre-monitoring and ongoing monitoring based on the original post-handling mechanism, to realize a full control on logistics finance risks. It is required to pay attention to the following points during establishing alarming mechanism of logistics finance business: It is required to select different alarming signals according to different risks, and utilize technical methods to analyze core enterprises on supply chain, as well as information such as operation situation, financial situation and loan repayment etc. of middle and small-sized enterprises; it is required to enhance risk information source, especially information on enhancing analysis on enterprise's trading and financial situation etc., to nip in the bud; for alarming information on various levels about logistics finance, Taobao Newbie needs to establish a corresponding report system, to guarantee in-time transmission of alarming information.

Second, establish its own safeguarding system. Taobao Newbie's developing logistics finance needs to establish a complete logistics finance system including value assessment on enterprise's pledge, and assessment on enterprise's credit etc. On one hand, it is to avoid unsymmetrical information from enterprise applying for a loan and the bank; one the other hand, it is to establish a reasonable value assessment system on 
pledged commodities of the enterprise, to reduce risks generated by inappropriate assessment on pledged commodities of the enterprise.

\section{Conclusion}

Carry out analysis on risk issue about Taobao Newbie's developing logistics financial business using literature method and survey method. It is indicated by research that there're internal operation, policy environment and industry environment risks during Taobao Newbie's developing logistics finance. So countermeasures such as improving business process and monitoring system, supplementing policy defects and establishing risk alarming system etc. have been put forward. Research results have reference significance for e-shopping websites to avoid risks during developing logistics finance business.

\section{References}

[1] Xiong Sha. Study on Risk of Logistics Enterprise Participating in Logistics Finance Service. Changsha: Changsha University of Science \& Technology, 2014: 61-61.

[2] Zhao Zongfei. Analysis on Current Situation of Enterprise Financing. Financial Services Sector, 2012(4): 117-117.

[3] Li Qi: Study on Related Issues about China's Logistics Finance. Beijing Economy, 2013(07): 74-75.

[4] Peng Yang. Stock Pledge Financing Decision-making and Risk Analysis Based on Unified Credit Mode. Wuhan: Wuhan University of Science \& Technology, 2011. 